\title{
Biopsychosocial Determinants of Human Papilloma Virus Immunization in Women of Reproductive Age in Surakarta, Central Java
}

\author{
Gabriela Advitri Febriani'), Setyo Sri Rahardjo²), Bhisma Murti1) \\ 1)Masters Program in Public Health, Universitas Sebelas Maret \\ 2)Faculty of Medicine, Universitas Sebelas Maret
}

\begin{abstract}
Background: Cervical cancer ranks second as the cause of death in women worldwide. Cervical cancer is preventable by Human Papilloma Virus (HPV) immunization. It was hypothesized that use of HPV immunization is determined by biopsychosocial factors as involved in the Health Belief Model and Social Learning Theory. This study aimed to analyze the determinants of HPV immunization use in women of reproductive age.

Subjects and Method: This was an analytic observational study with a cross-sectional design. The study was conducted at Permata Harapan Clinic and Budi Sehat Laboratory Clinic, Surakarta, Central Java. The data were collected from February to March 2018. A sample of 200 women was selected by random sampling, consisting of 50 women undertaking screening and 150 women not undertaking screening. The dependent variable was HPV immunization. The independent variables were perceptions of susceptibility, seriousness, benefit, barrier, respectively, and self-efficacy, education, family income, employment status, family support, social environment, and cervical cancer screening. Data on HPV vaccine use were taken from medical record. The data were collected by questionnaire and analyzed by path analysis.

Results: Use of HPV immunization was directly associated with perceived susceptibility $(b=2.01$; 95\% $\mathrm{CI}=1.03$ to $3.00 ; \mathrm{p}<0.001)$, perceived seriousness $(\mathrm{b}=1.52 ; 95 \% \mathrm{CI} 95 \%=-0.08$ to 3.13 ; $\mathrm{p}=0.063)$, self efficacy $(\mathrm{b}=1.55 ; 95 \% \mathrm{CI}=0.05$ to $3.05 ; \mathrm{p}=0.043)$, and perceived barrier $(\mathrm{b}=-2.25$; $95 \% \mathrm{CI}=-3.22$ to $-1.28 ; \mathrm{p}<0.001)$. It was indirectly associated with perceived benefit, education, family income, employment status, family support, social environment, and cervical cancer screening.

Conclusion: Use of HPV immunization is directly associated with perceived susceptibility, perceived seriousness, self-efficacy, and perceived barrier. It is indirectly associated with perceived benefit, education, family income, employment status, family support, social environment, and cervical cancer screening.
\end{abstract}

Keywords: Human Papilloma Virus, immunization, women of reproductive age, health belief model, social learning theory

\section{Correspondence:}

Gabriela Advitri Febriani. Masters Program in Public Health, Universitas Sebelas Maret, Jl. Ir. Sutami No. 36 A, Surakarta, Indonesia. Email: gabrielaadvitri8@gmail.com.

Mobile: +6285743809055.

\section{BACKGROUND}

$\overline{\text { Cervical cancer is at the second place after }}$ breast cancer as the cause of death and malignancy in women in the world. The incidence of cervical cancer causes deaths of about 275,000 per year with an estimated 500,000 new cases each year.
The number of cases of cervical cancer in Indonesia is 20,928 per year with the mortality rate of 9.498 per year (Cunningham et al., 2017; Brunni et al., 2017; Wiebe et al., 2012; WHO, 2017). Most cervical cancer patients in East Java are 21,313 people followed by Central Java for about 
Journal of Health Promotion and Behavior (2018), 3(1): 66-77

https://doi.org/10.26911/thejhpb.2018.03.01.07

19,739 people (Infodatin, 2015). The main cause of cervical cancer is a persistent infection by Human Papilloma Virus (HPV) especially type 16 and 18 (HPV Information Center, 2017). In 2006, two HPV vaccines have been licensed and marketed in many countries around the world. Although HPV vaccine is effective in preventing infection, the vaccination coverage is not optimal in most countries (Fernández et al., 2014).

Several studies have shown that psychosocial and sociodemographic factors such as perceptions of susceptibility to HPV infection and cervical cancer, vaccine effectiveness, safety and side effects of vaccines, concerns that vaccines will trigger free sex, race, education, family income and the availability of health insurance affect the use of vaccinations HPV (Fernández et al., 2014; Alberts et al., 2017). Two of the recommended models for explaining and understanding health behavior are the Health Belief Model (HBM) and Social Learning Theory.

This study aimed to analyze the biopsychosocial determinant of HPV vaccine use using Health Belief Model and Social Learning Theory.

\section{SUBJECTS AND METHODS \\ 1. Study Design \\ This was an analytic observational study with a case control desing. The study was conducted at Permata Harapan Clinic and Clinical Laboratory of Budi Sehat, Sura- karta, Central Java, from February from March of 2018.}

\section{Population and Sample}

The population in this study were women who received HPV vaccine and who did not receive HPV vaccine. A sample of 200 women consisting of 50 women with HPV vaccine and 150 women without HPV vaccine was selected by fixed disease sampling.

\section{Study variable}

The dependent variable is HPV vaccination. The independent variables are perception of vulnerability, perception of seriousness, perception of benefits, perception of barriers, self efficacy, family support, education, family income, employment status, social environment and cervical cancer screening.

\section{Operational definition of variables}

Perceived susceptibility was defined as positive or negative assessments of the risk for cervical cancer. It was measured using questionnaires. The measurement scale was continuous, but for the purpose of data analysis, it was transformed into dichotomous coded o for low and 1 for high.

Perceived seriousness was defined as the individual's subjective perceptions of how severe the physical and social consequences of cervical cancer. It was measured by questionnaires. The measurement scale was continuous, but for the purpose of data analysis, it was transformed into dichotomous coded o for low and 1 for high.

Perceived benefit was defined as the perceived confidence of individuals on the benefits of HPV vaccination to reduce the risk of cervical cancer. It was measured by questionnaires. The measurement scale was continuous, but for the purpose of data analysis, it was transformed into dichotomous coded o for low and 1 for high.

Perceived barrier was defined as a belief that is an individual obstacle or barrier to HPV vaccination resulting in negative health action outcomes. It was measured by questionnaires. The measurement scale was continuous, but for the purpose of data analysis, it was transformed into dichotomous coded o for low and 1 for high.

Self efficacy was defined as the conviction / ability of within a person to do HPV vaccination. It was measured by 
questionnaires. The measurement scale was continuous, but for the purpose of data analysis, it was transformed into dichotomous coded o for low and 1 for high.

Family support was defined as the support provided by the family that includes attitudes, behaviors manifested in actions so that women received HPV vaccinations. It was measured by questionnaires. The measurement scale was continuous, but for the purpose of data analysis, it was transformed into dichotomous coded o for weak and 1 for strong.

The level of education was defined as the level of formal education last pursued to get a diploma. It was measured by questionnaires. The measurement scale was categorical.

Income was defined as the amount of money received by an individual or company of its activities, measured using questionnaires. It was measured by questionnaires. The measurement scale was continuous, but for the purpose of data analysis, it was transformed into dichotomous coded o for low and 1 for high.

Occupation was defined as the main activity, task or work performed by the individual. It was measured by questionnaires. The measurement scale was categorical.

Social environment was defined as a process of learning that is done through observation of the behavior of other individuals who are considered to have more value. It was measured by questionnaires.
The measurement scale was continuous, but for the purpose of data analysis, it was transformed into dichotomous.

Cervical cancer screening was defined as the examination of visual inspection acetate acid or pap smear done to detect the existence of abnormalities. It was measured by questionnaires. The measurement scale was categorical.

HPV vaccination was defined as a vaccine conducted to prevent the occurrence of diseases caused by HPV viruses. It was measured by medical record. The measurement scale was categorical.

\section{Data analysis}

Univariate analysis was conducted to see the frequency distribution and percentage characteristics of the subjects. Bivariate analysis was conducted to study the relationship between HPV vaccine and the independent variables using chi-square test and odds ratio (OR) with 95\% confidence level (CI). Furthermore, multivariate analysis was done using path analysis.

\section{Research Ethics}

The research ethics included informed consent, anonymity, confidentiality and ethical clearance. The ethical clearance in this study was conducted at Dr. Moewardi hospital, Surakarta.

\begin{tabular}{l}
\hline RESULTS \\
1. Subjects characteristics \\
The frequency distribution of the \\
characteristics of the study subjects is \\
described in Table 1.
\end{tabular}
Table 1. The distribution of subjects by age and marital status

\begin{tabular}{clcc}
\hline No & Characteristics & Frequency (n) & Percentage (\%) \\
\hline 1 & Age (Year) & & \\
& $<38$ & 98 & 49 \\
& $\geq 38$ & 102 & 51 \\
2 & Marital status & & \\
& Single & 20 & 10 \\
& Married & 180 & 90 \\
\hline
\end{tabular}


Journal of Health Promotion and Behavior (2018), 3(1): 66-77

https://doi.org/10.26911/thejhpb.2018.03.01.07

\section{Path Analysis}

The results of the research analyzed using STATA 13 are presented as follows: the number of measured variables was 12, endogenous variables were 9, and exoge- nous variables were 3 , so the degree of freedom (df) was 54. df over identified value was obtained which means that path analysis can be done.

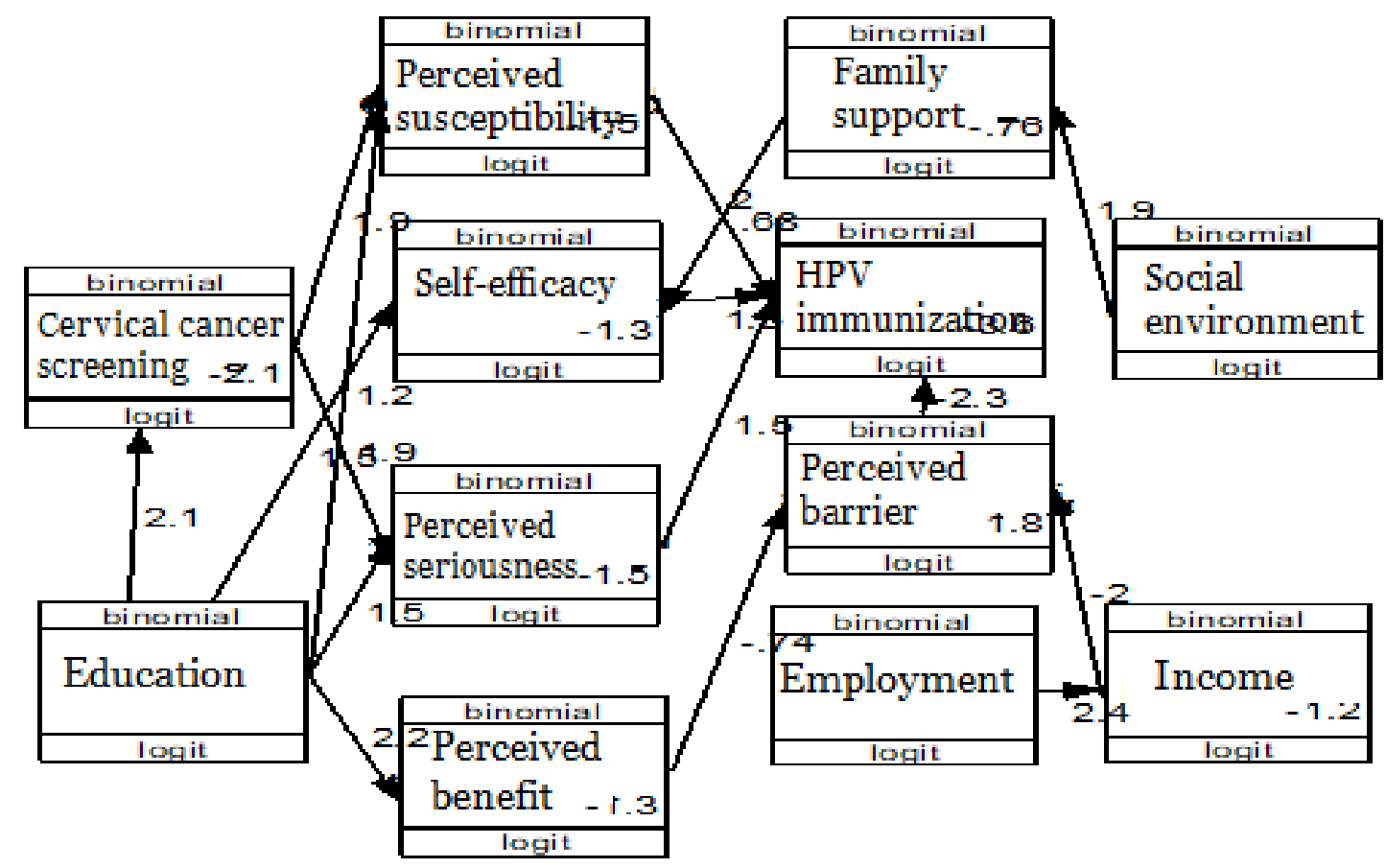

Figure 1. Structural model of path analysis

There was a relationship between perceived susceptibility and HPV immunization. Women with high perceptions of susceptibility were more likely to use HPV immunization $(\mathrm{b}=2.01 ; 95 \% \mathrm{CI}=1.03$ to 3.00; $\mathrm{p}<0.001$ ).

There was a relationship between perceived seriousness and HPV immunization. Women with high perceived seriousness were more likely to use HPV immunization $(b=1.52 ; 95 \% \mathrm{CI}=-0.08$ to 3.13 ; $\mathrm{p}=0.063)$.

There was a relationship between perceived barrier and HPV immunization. Women with high perceived barrier were less likely to use HPV immunization ( $b=-$ $2.25 ; 95 \% \mathrm{CI}=-3.22$ to $-1.28 ; \mathrm{p}<0.001$ ).

There was a relationship between self efficacy and HPV immunization. Women with strong self efficacy were more likely to use HPV immunization $(\mathrm{b}=1.55 ; 95 \% \mathrm{CI}=$ 0.05 to $3.05 ; \mathrm{p}=0.043$ ).

There was a relationship between education level and self efficacy. Women with higher education level was more likely to have strong self-efficacy $(b=1.53 ; 95 \%$ $\mathrm{CI}=0.88$ to $2.19 ; \mathrm{p}<0.001$ ).

There was a relationship between family support and self efficacy. Women with strong family support were more likely to have strong self-efficacy $(\mathrm{b}=0.68 ; 95 \%$ $\mathrm{CI}=0.08$ to $1.28 ; \mathrm{p}=0.027$ ).

There was a relationship between income and perceived barrier and. Women with high income were less likely to have high perceived barrier $(b=-2.00 ; 95 \% \mathrm{CI}=-$ 2.67 to $-1.34 ; \mathrm{p}<0.01$ ). 
There was a relationship between perceived benefit and perceived barrier. Women with high perceived benefit were less likely to have high perceived barrier $(\mathrm{b}=-0.74 ; 95 \% \mathrm{CI}=-1.37$ to $-0.10 ; \mathrm{p}=$ $0.023)$.

Table 2. Results of path analysis on the biopsychosocial determinants of HPV immunization in reproductive age women

\begin{tabular}{|c|c|c|c|c|c|c|}
\hline \multirow[b]{2}{*}{ Dependent Variable } & & \multirow[b]{2}{*}{ Independent Variable } & \multirow[b]{2}{*}{ b } & \multicolumn{2}{|c|}{$95 \% \mathrm{Cl}$} & \multirow[b]{2}{*}{$\mathbf{p}$} \\
\hline & & & & $\begin{array}{c}\text { Lower } \\
\text { limit }\end{array}$ & $\begin{array}{l}\text { Upper } \\
\text { limit }\end{array}$ & \\
\hline \multicolumn{7}{|l|}{ Direct Effect } \\
\hline HPV immunization use & $\leftarrow$ & High perceived & & & & \\
\hline & & susceptibility & 2.01 & 1.03 & 3.00 & $<0.001$ \\
\hline HPV immunization use & $\leftarrow$ & High perceived & & & & \\
\hline & & seriousness & 1.52 & -0.08 & 3.13 & 0.063 \\
\hline HPV immunization use & $\leftarrow$ & High perceived barrier & -2.25 & -3.22 & -1.28 & $<0.001$ \\
\hline HPV immunization use & $\leftarrow$ & Self-efficacy & 1.55 & 0.05 & 3.05 & 0.043 \\
\hline \multicolumn{7}{|l|}{ Indirect Effect } \\
\hline Self-efficacy & $\leftarrow$ & $\begin{array}{l}\text { Education } \geq \text { Senior high } \\
\text { school }\end{array}$ & 1.53 & 0.88 & 2.19 & $<0.001$ \\
\hline Self-efficacy & $\leftarrow$ & Strong family support & 0.68 & 0.08 & 1.28 & 0.027 \\
\hline High perceived barrier & $\leftarrow$ & High income & -2.00 & -2.67 & -1.34 & $<0.001$ \\
\hline High perceived barrier & $\leftarrow$ & High perceived benefit & -0.74 & -1.37 & -0.10 & 0.023 \\
\hline High perceived & $\leftarrow$ & Education $\geq$ Senior high & & & & \\
\hline seriousness & & school & 1.50 & 0.77 & 2.24 & $<0.001$ \\
\hline High perceived & $\leftarrow$ & Cervical cancer screening & & & & \\
\hline seriousness & & & 1.94 & 1.17 & 2.71 & $<0.001$ \\
\hline High perceived & $\leftarrow$ & Education $\geq$ Senior high & & & & \\
\hline susceptibility & & school & 1.19 & 0.46 & 1.92 & 0.001 \\
\hline High perceived & $\leftarrow$ & Cervical cancer screening & & & & \\
\hline susceptibility & & & 1.89 & 1.17 & 2.61 & $<0.001$ \\
\hline \multirow{3}{*}{ Perceived benefits } & $\leftarrow$ & $\begin{array}{l}\text { Education } \geq \text { Senior high } \\
\text { school }\end{array}$ & 2.01 & 1.25 & 2.95 & $<0.001$ \\
\hline & $\leftarrow$ & Education $\geq$ Senior high & & & & \\
\hline & & school & 2.16 & 1.46 & 2.86 & $<0.001$ \\
\hline High income & $\leftarrow$ & Occupational & 2.44 & 1.76 & 3.12 & $<0.001$ \\
\hline Family Support & $\leftarrow$ & Strong social environment & 1.94 & 1.31 & 2.56 & $<0.001$ \\
\hline $\mathrm{N}$ Observation $=200$ & & & & & & \\
\hline Log Likelihood $=-971.53$ & & & & & & \\
\hline
\end{tabular}

There was a positive association between education and perceived seriousness. Women with higher education were more likely to have a high perceived seriousness $(b=1.50 ; 95 \% \mathrm{CI}=0.77$ to 2.24; $\mathrm{p}<0.001$ ).

There was a positive association between cervical cancer screening and perceived seriousness. Women who have cervical cancer screening had a greater likelihood of having a high perceived seriousness $(\mathrm{b}=1.94 ; 95 \% \mathrm{CI}=1.17$ to 2.71 ; $\mathrm{p}<0.001)$.

There was a positive association between education and perceived susceptibility. Women with higher education were more likely to have a high perceived susceptibility $(b=1.19 ; 95 \% \mathrm{CI}=0.46$ to 1.92; $\mathrm{p}=0.001$ ).

There was a positive association between cervical cancer screening and perceived susceptibility. Women who had 
cervical cancer screening had a greater likelihood of high perceived susceptibility $(\mathrm{b}=1.89 ; 95 \% \mathrm{CI}=1.17$ to $2.61 ; \mathrm{p}<0.001$ ).

There was a positive association between education and cervical cancer screening. Women with higher education were more likely to had cervical cancer screening ( $b=2.01 ; 95 \% \mathrm{CI}=1.25$ to 2.95 ; $\mathrm{p}<0.001)$.

There was a positive association between employment and income. Women who work outside the house were more likely to had high income $(b=2.44 ; 95 \%$ $\mathrm{CI}=1.76$ to $3.12 ; \mathrm{p}<0.001$ ).

\section{DISCUSSIONS}

\section{The relationship of perceived sus- ceptibility and HPV immunization}

The result of this study showed that there was a direct relationship between perceived susceptibility and HPV immunization. The relationship was positive and sigificant. The result of this study was in line with a study by Roberts et al (2015) which stated that there was a positive relationship between vulnerability perceptions and the action of HPV vaccine. A woman's perception that she was vulnerable to HPV infection in the future was a strong motivation for HPV vaccine. This study was supported by a study of Cox et al. (2010) and Thomas et al. (2017) which stated that parental intention to vaccinate their children was influenced by their child's susceptibility to HPV infection, severity infections, vaccine efficacy, and immunization barriers.

\section{The relationship of perceived per- ception seriousness and HPV immunization}

The result of analysis showed that there was a direct relationship between perceived seriousness and HPV vaccine. The result of this study is consistent with Kyoung et al. (2018), which stated that women with high levels of education, greater knowledge, awareness of HPV infection and vaccination, and a high perceived seriousness about HPV infection have a strong desire to vaccinate and were more likely to vaccinate their daughters as well. Tan et al. (2017) added that the lack of understanding and perception toward the dangers of HPV infection became a barrier to HPV vaccine. The role of health personnel to provide information about diseases caused by HPV virus and HPV vaccination was highly important.

\section{The relationship of perceived} barrier and HPV immunization

The result of analysis showed that there was a direct relationship between perceived barrier and HPV vaccine. The result of this study is consistent with Kyoung et al. (2018) which described that there were many reasons for the refusal to do HPV vaccination, which were lack of awareness, high cost, the effectiveness of vaccines, and adverse reactions/side effects when doing HPV vaccine. Beavis et al. (2016) stated that the coverage of HPV vaccine in the United States has decreased, this was influenced by low socioeconomic where women with low socioeconomic status tend to ignore to start and finish the dose of HPV vaccine, in addition, limited access to health services, misperception by doctors and patients, and health insurance that ensured the use of HPV vaccine were also women's considerations in doing HPV vaccine. Saqer et al. (2017) added that religious values were also the determinant in doing HPV vaccine.

\section{The relationship of self-efficacy and HPV immunization}

The result of analysis showed that there was a direct relationship between selfefficacy and HPV vaccine. This study was supported by a study done by Forster et al., (2017), which stated that knowledge of HPV and HPV vaccine affected teenagers' fear, 
anxiety, and confidence to make decisions on doing HPV vaccine. This study was also supported by Cox et al., (2010) who stated that parents' beliefs to vaccinate their children because HPV was a serious disease and it can caused cancer. Parents' decision to vaccinate their children also depend on the provision of vaccines by health care providers.

\section{The relationship of education and HPV immunization}

The result of analysis showed that there was an indirect relationship between education level and HPV vaccine through self-efficacy, perceived seriousness, perceived susceptibility, cervical cancer screening, and perceptions of benefit. The direct correlation between level of education with self efficacy, perception of seriousness, perception of susceptibility, cervical cancer screening, and perception of benefit was positive and statistically significant. This was in line with the result of a study by Cipriano et al. (2018) which stated that parents with high level of education have a good acceptance of HPV vaccination in their children. Parents with low education tend to be mistaken in receiving information about HPV vaccine. A low level of education affected the knowledge about HPV risk and self-efficacy in HPV vaccine (McBride et al, 2018).

This was in line with the result of the study by McBride et al (2018) which stated that sociodemography such as gender, age, education level, relationship status, income, and race of a person affected the awareness and knowledge about the risks and seriousness of HPV infection that can caused cancer and non-cancer diseases. A study by Kyoung et al. (2018) stated that highlyeducated women have greater knowledge and awareness of HPV infection and vaccine as well as a high perception of seriousness about HPV infection, therefore, they have a great desire to vaccinate and were more likely to vaccinate their daughters as well.

Nan et al (2016) reported that parents with a high education have a perception that their child was vulnerable to HPV infection so they have the intention to vaccinate their children and assumed that the vaccine was beneficial. Parents who assumed that their children were not susceptible to HPV infection would feel greater losses if they vaccinate their children especially in terms of cost. A study by Baumeister et al. (2007) added that women in India with an average education level agreed that all women regardless of age were susceptible to cervical cancer and knew that cervical cancer was difficult to cure.

This study was supported by a study done by Ndejjo et al. (2017), which stated that highly-educated women who live in rural area in Uganda, those who were already screened could access information about cervical cancer from radio and health facilities. Most participants believed that cervical cancer can be prevented after understanding the cause of the disease, how it can be avoided and known through cervical cancer screening. A study by Baumeister et al. (2007) described that in women with the majority of average education in India found that at least 10\% of women performed one screening, the availability of health insurance with awareness and knowledge about the risk of cervical cancer were the reasons for doing the screening. However, there were many barriers that have been found in Indian women decision to do screening, they were lack of information, anxiety about test results, not knowing the place to do screening, and high costs.

Nan et al. (2016) stated that sociodemography became the determinant factor 
Journal of Health Promotion and Behavior (2018), 3(1): 66-77

https://doi.org/10.26911/thejhpb.2018.03.01.07

for parental decision to vaccinate their children. Sociodemography including age, gender, and level of education. Highly-educated parents believed that their children were at risk of HPV infection and that HPV vaccine was harmless and has substantial benefits. A study by Sari et al. (2016) stated that women's educational level could support the knowledge that they have. Highly-educated women have broader information and knowledge than women with low levels of education. Low level of education caused a person to be careless to existing health programs and the risks that would occur.

\section{The relationship of family income and HPV immunization through self-efficacy}

The result of analysis showed that there was an indirect relationship between family income and HPV vaccine through selfefficacy. The direct correlation between family income and self-efficacy was positive and statistically significant. This study was supported by a study done by Dairo et al (2016) which stated that family support, especially parents supported by knowledge, awareness, and economic levels reinforced parents' confidence to do HPV vaccine and vaccinate their children. This study was also supported by Thomas et al. (2017) dan Saqer et al. (2017) who stated that the role of both parent and spouse was also supported by the government's role in recommending HPV vaccine to give the conviction and willingness to do HPV vaccine to both women and parents who have children.

\section{The relationship of perceived barriers and HPV immunization}

The result of analysis showed that there was an indirect relationship between perceived barrier and HPV vaccine through income and perceptions of benefit. This study was is consistent with Beavis et al.
(2016), which stated that low socioeconomic status became one of the obstacles felt by women in the United States to start and finish the doses of the HPV vaccine. According to the research by Hoffmann et al. (2008), people with low income became one of the barriers to access health services, this was related to the transportation to health center and the costs of redeeming the prescriptions, consultations, and treatments.

According to Rey et al., (2018), there were many factors that make parents and women hesitant to use vaccines, research conducted in France stated that the coverage of vaccines especially HPV was still low in that country because they felt the benefits of vaccines which were not comparable with the risks to be received such as the sexual behavior of their children after the vaccine, effectiveness, and safety of the vaccine. Parents considered the threat of HPV infection was lower than other diseases so that HPV vaccine was not necessary. The unavailability of recommendations from doctors and health personnel has also been one of the obstacles in HPV vaccine coverage. A study by Karafillakis et al (2017) added that the communication of HPV vaccine from health personnel to improve the public perceived benefits, risks, side effects, and safety of the HPV vaccine was needed, in addition, the number HPV vaccine acceptors being sampled by health personnel was also an obstacle to the low coverage of HPV vaccine.

\section{The relationship of cervical cancer screening and HPV immunization}

The result of analysis showed that there was an indirect relationship between cervical cancer screening and HPV vaccine through perceptions of seriousness and perceptions of vulnerability. The direct relationship between cervical cancer screening and perceptions of seriousness 
was positive and statistically significant. A study by Barroeta et al. (2017) stated that pap smear screening was still needed both in women who have not or have already done HPV vaccine. The reason of women to routinely do pap smear screening was because they realized that HPV can caused cervical cancer. In Italy, the screening and vaccination programs were comprehensive, the consensus group had set specific recommendations for primary HPV and HPV vaccination as two prevention strategies. A study by Wang et al. (2015) in China found that women who did pap smears have a high awareness about health. The low coverage of pap smears in rural China was influenced by socioeconomic and availability of health facilities with screening programs.

A study by Cunningham et al. (2015) reported that the prevalence of cervical cancer screening in both rural and urban women was low. However, in terms of personal risks for cervical cancer, the majority of women felt that they were susceptible to cervical cancer. The result of a study by Ndejjo et al. (2017) in women in rural Uganda revealed the poor knowledge about the causes of cervical cancer, signs and symptoms, screening methods, and prevention. However, they considered themselves at risk for cervical cancer, and the perception of risk was the determinant to do cervical cancer screening. The barriers to do cervical cancer screening reported were lack of knowledge about cervical cancer and screening, health system challenges, fear of test results, and financial constraints.

\section{The relationship of occupational and HPV immunization through income}

The result of analysis showed that there was an indirect relationship between employment status and HPV immunization through income. This study was supported by a study done by Lim et al. (2015), which stated that employment status affected the income. A person with a permanent employment status has a higher income than a person with a temporary employment status. This affected the awareness of health, where a person with a permanent employment status has a higher awareness of health. This study was also supported by a study of Senicato et al. (2016), which stated that women who did not work/ housewives have low income because they did not receive salary and rely on other family members. Women who did not work with low socioeconomic status (education and low income) have less autonomy and few prospects of development and personal satisfaction, compared to working women from the same social status. Working women have a higher awareness of health because women with poor health status have less chance of being accepted and survived in the labor market.

\section{The relationship of social envi- ronment and HPV immunization through family support}

The result of analysis showed that there was an indirect relationship between social environment and HPV vaccine through family support. This study was supported by Cunningham et al. (2015) which stated that the lack of social support can be a barrier to women in screening especially when they have to travel long distances to health facilities. Social support could be obtained from social organizations that were followed including support from family members, spouses, and friends. This study was also supported by Senicato et al. (2016), which stated that working women have confidence and skills development to deal with stressful situations and facing social networking development that 
affected family intimacy, as well as social support.

\section{REFERENCE}

$\overline{\text { Alberts CJ, Loeff MFC, Hazeveld Y, Melker }}$ HE, Wal MF, Nielen A, Fakiri FE, Prins M, Pulussen TGWM (2017). A Longitudinal Study on Determinants of HPV Vaccination Uptake in Parents/Guardians from Different Ethnic Background in Amsterdams the Netherlands. BMC Public Health. 17: 220.

Barroeta JE, Guragain DA, Grotkowski CE (2016). Cervical cancer screening in the era of HPV vaccination: A review of shifting paradigms in cytopathology. Wiley Periodicals.

Baumesiter RF, Vohs KD (2008). Self-Regulation, Ego Depletion, and Motivation. Social and Personality Psychology Compass.

Beavis AL, Levinson KL (2016). Preventing Cervical Cancer in the United States: Barriers and Resolutions for HPV Vaccination. Front. Oncol.

Brunni L, Barrionuevo-Rosas L, Albero G, Serrano B, Mena M, Gómez D, Muñoz J, Bosch FX, de Sanjosé S (2017). Human Papillomavirus and related diseases in The World. ICO Information Centre on HPV and Cancer.

Cipriano JJ, Scoloveno R, Kelly A (2017). Increasing Parental Knowledge Related to the Human Papillomavirus Vaccine (HPV). National Association of Pediatric Nurse Practitioners.

Cox DS, Cox AD, Sturm L, Zimet G (2010). Behavioral Interventions to Increase HPV Acceptability Vaccination Among Young Mothers Girls. American Psychological Association: health psychology.

Cunningham MS, Skrastins E, Fitzpatrick R, Jindal P, Oneko O, Yeates K, Booth
CM, Carpenter J, Aronson K (2017). Cervical Cancer Screening and HPV Vaccine Acceptability among Rural and Urban Women in Kilimanjaro Region Tanzania. BMJ Open. 5: eo05828.

Dairo MD, Adeleke MO, Salawu AT, Adewole AD (2016). Parental support for human papilloma virus vaccination by adolescents in Ibadan North Local Government Area, Ibadan, Nigeria. Adolescent Medicine and Health.

Fernandez ME, Yen-Chi, Espada NF, Calo WA, Savas LS, Velez C, Aragon AP, Lopez VC (2014). Knowledge, Attitudes and Beliefs About Human Papillomavirus (HPV) Vaccination among Puerto Rican Mothers and Daughters. Center for Disease Control and Prevention. 11 E212.

Forster AS, McBride KA, Davies C, Stoney T, Marshall H, McGeechan K, Cooper SC, Skinner SR (2017). Development and Validation of Measures to Evaluate Adolescent Knowledge about Human Papillomavirus (HPV) involvement in HPV Vaccine decisionmaking, self-efficacy to receive the Vaccine and fear and anxiety. The Royal Society for Public Health.

Hoffmann RL, Rohrer WM, Paul JES, Burdett R, Watziaf VJM (2008). The Effects of Barriers on Health Related Quality of Life (HRQL) and Compliance in Adult Asthmatics who are Followed in an Urban Community Health Care Facility. J Community Health.

HPV Information Center (2017). Human Papillomavirus and Related Disease Report. ICO HPV Information Center. Infodatin (2015). Stop Kanker. Pusat Data dan Informasi Kementrian Kesehatan RI: 2-4. 
Karafillakis E, Larson HJ (2017). The Benefit of the doubt or doubts over benefits? A systematic literature review of perceived risks of vacinnes in European populations. Vaccine.

Kyoung J, Jeong BY, Yun EH, Lim MK (2017). Awareness of and Attitudes toward Human Papillomavirus Vaccination among Adults in Korea: 9-Year Changes in Nationwide Surveys. Cancer Research and Treatment: Official Journal of Korean Cancer Association.

Lim H, Kimm H, Song IH (2014). The Relationship between Employment Status and Self-rated Health among Wage Workers in South Korea: The Moderating Role of Household Income. Health and Social Works.

Mc Bride KR, Singh S (2017). Predictors of Adults' Knowledge and Awareness of HPV, HPV-Associated Cancers, and the HPV Vaccine: Implications for Health Education. Health Education \& Behavior.

Nan X, Madden K, Richards A, Holt C, Wang MQ, Tracy K (2015). Message Framing, Perceived Susceptibility, and Intentions to Vaccinate Children Against HPV Among African American Parents. Health Communication.

Ndejjo R, Mukama T, Kiguli J, Musoke D (2017). Knowledge, facilitators and barriers to cervical cancer screening among women in Uganda: a qualitative study. BMJ Journals.

Rey D, Fressard L, Cortaredona S, Bocquier A, Gautier A, Watel PP, Verger P (2018). Vaccine hesitancy in the French population in 2016, and its association with vaccine uptake and perceived vaccine risk-benefit balance. Eurosurveillance.
Roberts ME, Gerrard M, Reimer R, Gibbons FX (2015). Mother-Daughter Communication and Human Papillomavirus Vaccine Uptake by College Students. Pediatrics.

Saqer A, Ghazal S, Barqawi H, Babi JA, Alkhafaji R, Elmekresh MM (2017). Knowledge and Awareness about Cervical Cancer Vaccine (HPV) Among Parents in Sharjah. Asian Pacific Journal of Cancer Prevention.

Sari HE, Mudigdo A, Dermatoto A (2016). Multilevel Analysis on the Social Determinants of Cervical Cancer in Yogyakarta. Journal of Epidemiology and Public Health.

Senicato C, Lima MG, Barros MB (2016). Are there differences between paid women workers and housewives in health-related quality of life?. SciELO: Cadernos de Saude Publica.

Tan TQ, Melvin V, Gerbie MD (2017). Perception, Awareness, and Acceptance of Human Papillomavirus Disease and Vaccine Among Parents of Boys Aged 9 to 18 Years. Clinical Pediatrics.

Thomas TL, Strickland OL, Higgins M (2017). Mothers, Fathers, Sons, and Human Papillomavirus Immunization Practices. Family and Community Health.

Wang B, He M, Chao A, Engelgau MM, Saraiya M, Wang L, Wang L (2015). Cervical Cancer Screening Among Adult Women in China. The Oncologist.

WHO (2017). Immunization, Vaccines and Biologicals Human Papillomavirus. Geneva: World Health Organization.

Wiebe E, Denny L, Thomas G (2012). Cancer of The Cervix Uteri. International Journal of Gynecology and Obstetrics. 